\title{
Exploração sexual e trabalho na adolescência: Um estudo de caso
}

\author{
Sexual exploitation and labor during adolescence: \\ A case study
}

Recibido: agosto 5 de 2009 ～Revisado: diciembre 14 de 2009 Aceptado: mayo 10 de 2010

\section{LUCIANA DUTRA-THOMÉ* \\ Elder Cerqueira SANTOS \\ Silvia Helena Koller}

Universidade Federal do Rio Grande do Sul, Brasil

\section{RES UMO}

O presente artigo teve como foco a exploração sexual percebida como trabalho, com delineamento de estudo de caso único. O objetivo foi investigar o caso de uma menina de 14 anos, em situação de exploração sexual comercial, que informava em uma entrevista semi-estruturada, ser esta a sua atividade laboral. Foram levantadas categorias relacionadas aos fatores de risco e de proteção na vida da jovem, especialmente relacionados ao trabalho. Constatou-se que a jovem percebia a atividade como um trabalho que lhe proporcionava autonomia, subsistência e sobrevivência. No entanto, os efeitos negativos da exploração sexual e de sua percepção desta como atividade laboral eram evidentes sobre sua saúde e seu desenvolvimento. O trabalho juvenil pode ser considerado um fator de risco, como no presente estudo de caso, principalmente quando as condições laborais não se dão de forma adequada e protegida.

Palavras-chave autores

Adolescência, trabalho, fatores de risco e proteção, exploração sexual.

Palavras-chave plus

Psicología del desarrollo, investigación cualitativa, estudio de caso.

Para citar este artículo. Dutra-Thomé, L., Cerqueira-Santos, E. \& Koller, S. H. (2011). Exploração sexual e trabalho na adolescência: Um estudo de caso. Universitas Psychologica, 10 (3), 881-896.

* Rua Ramiro Barcelos, 2600 - Bairro Santa Cecília, Porto Alegre, RS, Brasil, CEP 90035-003. E-mails: lucianaduth@gmail.com, eldercerqueira@yahoo. com.br, silvia.koller@gmail.com

\section{A B S T R A C T}

The present article focused on the perception of sexual exploitation as a job, using a single case study design. The aim of the study was to investigate the case of a 14 year-old girl, involved in commercial sexual exploitation, who considered this situation as her labor activity. A content analysis showed protective and risk factors as categories, especially related to her labor activities. The girl perceived the sexual exploitation activity as a job that provided autonomy, subsistence, and survival. The study revealed that the negative effects of working during adolescence may bring consequences to health and development. Youth work may be defined as a risk factor, especially when the labour conditions are not adequate and protected.

Key words authors

Adolescence, work, protective and risk factors, sexual exploitation.

Key words plus

Developmental psychology, qualitative research, case study. 
A exploração sexual de crianças e adolescente (ESCA) é uma violação dos direitos da criança e do adolescente, e tem sido considerada dentro do grande tema da violência sexual, diferenciandose do abuso sexual pelo seu caráter comercial (ver Figura 1). Junto com o tráfico de drogas, caracteriza-se como uma das piores formas de trabalho infanto-juvenil. Atividades dessa natureza distanciam-se das diretrizes do Estatuto da Criança e do Adolescente (ECA, 1990), as quais definem que é proibido qualquer trabalho a menores de quatorze anos, salvo na condição de aprendiz (Artigo 60). Quando existente, deve ocorrer de forma protegida - sem prejudicar a educação e a vida comunitária do indivíduo em desenvolvimento.

A violência sexual contra os adolescentes é evidenciada por qualquer atividade entre um adolescente e um adulto ou outro adolescente que, pela idade ou estágio do desenvolvimento, está em uma relação de responsabilidade, confiança ou força. A atividade sexual, nestes casos, é destinada para gratificação ou satisfação das necessidades desta outra pessoa adulta ou mais forte. Isto pode incluir (mas não se limita) a indução ou coerção de um(a) adolescente para engajar-se em qualquer atividade sexual, a exploração de um(a) adolescente em sexo comercial ou outra prática sexual ilegal e o uso de adolescentes em performances ou materiais pornográficos (World Health Organization, 1999). Esta definição vale quando a atividade sexual é dirigida ou envolve também crianças. Tal violação de direitos, que antes do ECA (1990) era conhecida como prostituição infanto-juvenil, passa a ser denominada, de acordo com Leal (1999), como exploração sexual infanto-juvenil. Desta forma, muda-se o foco dos adolescentes como atores para vítimas da situação, tirando a autonomia e evidenciando a prática criminosa de outros (Serpa, 2009). Nesse sentido, o foco da vitimização deve orientar a compreensão do fenômeno, considerando que a atividade de venda do corpo para fins sexuais torna-se uma experiência presente na vida do(a) jovem que a executa e, portanto, constituinte de sua identidade.

A atividade sexual envolvendo exploração comercial está relacionada ao uso do corpo adolescente por troca por dinheiro, satisfação de necessidades básicas e/ou de consumo (Faleiros, 2004). A lógica de mercado está presente na atividade, a partir da qual a pessoa pode arcar com suas necessidades financeiras. Portanto, a dimensão laboral está implicada no universo da exploração sexual. Caracteriza-se como uma forma de trabalho perversa, desprotegida e degradante. Neste contexto

FIGURA 1

Diferença entre abuso e exploração sexual no quadro da violência sexual

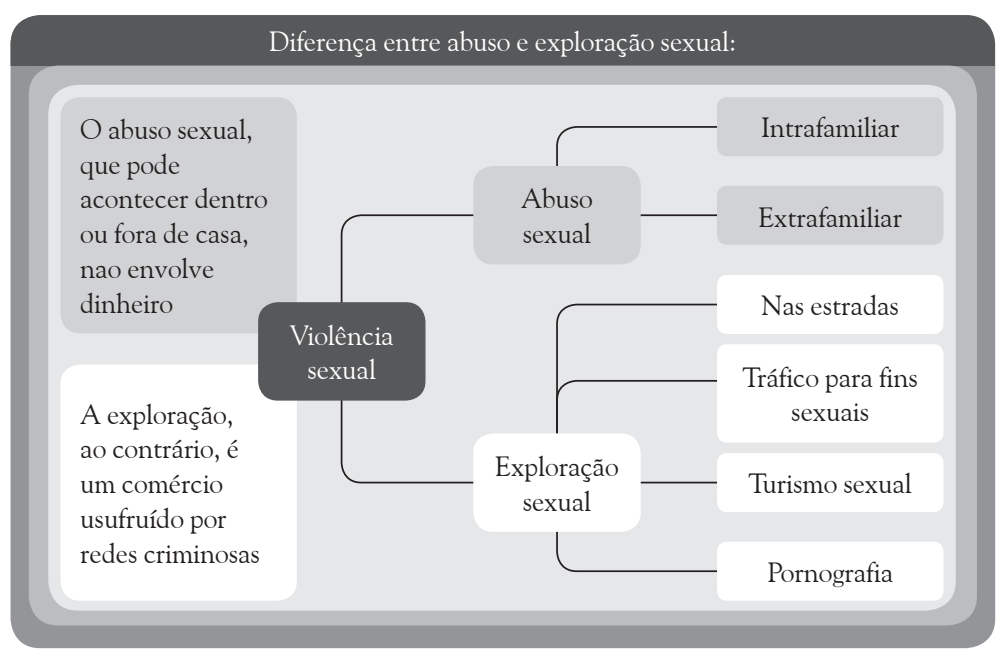

Fonte: www.namaocerta.org.br 
de análise, cabe resgatar que um dos significados conferidos ao termo trabalho é o de mercadoria, uma vez que o fazer profissional está ligado à atividade remunerada, cuja finalidade é proporcionar a sobrevivência dos indivíduos e a satisfação de suas necessidades (Zanini, Fürstenau, Pacini \& Merlo, 2004).

Para Libório (2005), a exploração sexual consiste em violência interpessoal, que ocorre em relações pessoais próximas, dentro ou fora da família. Estas favorecem a vulnerabilização das mulheres, crianças e adolescentes. Estes protagonistas estão inseridos em um mercado do sexo que utiliza o marketing e a publicidade para divulgar a hipererotização do corpo feminino, fortalecendo lógicas de submissão e desqualificação da mulher (Leal, 1999), independentemente de sua idade.

A exploração sexual é uma violência que gera trauma e que envolve fatores sociais, culturais ou econômicos, que afetam o desenvolvimento de crianças e adolescentes. Uma série de riscos é apresentada na vida de crianças e adolescentes expostos a esta condição. No entanto, estes riscos não aparecem apenas após o envolvimento concreto com a exploração sexual da própria criança/adolescente. Aspectos estruturais, familiares, sociais e pessoais podem anteceder esta concretização nas suas vidas, ou seja, crescer em uma família na qual o abuso sexual é corrente ou há a presença de outros fatores de risco, como empobrecimento, violência psicológica e física, uso de drogas e álcool, prostituição, conflitos com a lei, prisões, residência em comunidade violenta, desemprego, entre outros (Koller \& De Antoni, 2004).

Nesse contexto, é possível identificar a existência dos fatores de risco, que são aspectos pessoais, ambientais ou culturais que atuam como obstáculo ao desenvolvimento (em nível individual ou social) e que potencializam a vulnerabilidade das pessoas a resultados indesejáveis ao longo do seu ciclo vital (Pesce, Assis, Santos \& Oliveira, 2004). Em uma revisão sobre o abuso sexual contra crianças e adolescentes, Amazarray e Koller (1998) ressaltaram que as conseqüências deste tipo de violência para crianças e adolescentes podem ser físicas, emocionais, sexuais e sociais (comportamento interpessoal). Segundo De Antoni (2000), o abuso emocional ou psicológico é evidenciado pelo prejuízo à competência emocional das crianças/ adolescentes, influenciando principalmente sua capacidade de sentir emoções positivas por outros, de se sentirem bem consigo mesmas e de construir expectativas adequadas de futuro.

Fatores de proteção são definidos como aspectos pessoais ou do contexto, capazes de reduzir os efeitos dos fatores de risco e garantir o desenvolvimento humano daqueles expostos a eles (Masten, 2001). Componentes biológicos, como a saúde física e o temperamento, a experiência da pessoa com o ambiente, a constituição da auto-estima, auto-eficácia e a confiança são aspectos pessoais relevantes para a proteção. No ambiente, são considerados como fatores de proteção os aspectos socioeconômicos e a rede social e emocional de apoio gerada pela comunidade na qual a pessoa está inserida (De Antoni, 2000).

Uma análise bioecológica do desenvolvimento, segundo a proposta de Bronfenbrenner (1979/1996) e Bronfenbrenner e Morris (1998) considera a presença e associação de fatores de risco e de proteção. Como os elementos de análise da abordagem bioecológica do desenvolvimento humano levam em conta a pessoa, seus processos psicológicos, o momento de vida e sua história (tempo) e o seu ambiente de desenvolvimento (contexto), a influência da exploração sexual tem várias repercussões. A exposição a uma história de abuso e exploração influencia na forma como a pessoa se percebe e lida com as adversidades (processo), que pode variar a partir do contexto e do tempo no qual está vivendo (Cecconello, 2003).

A violência doméstica ou familiar, principalmente o abuso sexual, tem sido apontada como fator de risco para a exploração sexual. Para fugir dela, muitas vezes, adolescentes migram para as ruas (Raffaelli et al., 2001). Neste contexto e sem apoio, a exploração sexual passa a ser vista como uma estratégia de sobrevivência (Libório, 2005), no entanto, passam a estar expostos à violência social ou na comunidade. Conforme apontaram Verado, Reis e Veiga (1999), o corpo dos(das) adolescentes já foi usado como uma ferramenta 
de sedução e, com isso, passar a ser usado como estratégia para sobreviver pode ser algo previsível. Portanto, o envolvimento com a exploração sexual pode se apresentar como uma alternativa. Outros fatores de risco associados pela literatura com a exploração sexual são alto índice de uso de drogas (álcool, maconha, crack ou cocaína), assim como baixa escolaridade ou analfabetismo (Libório, 2005; Serpa, 2009).

Observa-se que, apesar da redução das piores formas de trabalho infanto-juvenil conquistada nos últimos anos, ainda persiste um amplo número de crianças e adolescentes que participam de atividades econômicas, entre as quais estão incluídas o tráfico de drogas e a exploração sexual. Além dos fatores econômicos, a complexidade do tema é perpassada por questões culturais e ideológicas, as quais estão intimamente associadas à dificuldade da erradicação do trabalho infantil e à mudança de comportamento necessária para tal finalidade (Amazarray, Dutra-Thomé, Poletto \& Koller, 2007).

A exploração da mão-de-obra infanto-juvenil está vinculada à fragilidade deste contexto, que, por vezes, incorpora crianças e adolescentes ao mercado de trabalho, enquanto, por outro lado, há mão-de-obra adulta excedente (Assunção \& Dias, 2002; Oliveira, 1987). A exploração do trabalho infanto-juvenil persiste na contemporaneidade devido a uma combinação de fatores, como a condição de miserabilidade e vulnerabilidade das famílias, a ausência de políticas públicas e a péssima distribuição de renda no Brasil (Marques, Neves \& Neto, 2002). Neste cenário, os jovens se vêem obrigados a trabalhar para garantir o próprio sustento ou de sua família. Não é incomum que o trabalho infanto-juvenil seja concebido como parte complementar das atribuições familiares, segundo a lógica das obrigações, que caracteriza as relações nas famílias carentes (Sarti, 1996).

De acordo com estimativa da Organização Internacional do Trabalho (OIT, 2006), existem no mundo mais de 246 milhões de crianças e adolescentes trabalhadores com idade entre cinco e 17 anos. Desses, mais de 100 milhões não têm acesso a qualquer tipo de educação e, para a maioria, tempo para brincar é um luxo que não está ao seu alcance. Segundo Barros e Santos (1996), o trabalho infanto-juvenil é um dos mecanismos de transmissão intergeracional da pobreza, especialmente porque, em geral, os pais das crianças trabalhadoras também realizaram esta atividade na sua infância.

Nesse contexto de análise, é pertinente situar o papel do trabalho na vida dos indivíduos, uma vez que os significados que permeiam a palavra trabalho perpassam, por exemplo, a idéia de reconhecimento social, viabilizado pela realização de uma obra capaz de expressar o ser humano (Albornoz, 1986). O trabalho também é descrito como constituinte da identidade do indivíduo, uma vez que aquilo que a pessoa produz transforma a si mesma e a natureza. As concepções marxistas compreendem que a essência do indivíduo encontra-se na atividade laboral (Jacques, 2003), contribuindo para a constituição do seu mundo psicológico e físico. Estas definições posicionam o trabalho num lugar de destaque para os seres humanos, o que pode estar relacionado com a ênfase dada pela própria participante na exploração sexual como atividade laboral, remunerada e para sobrevivência. Nesse sentido, esta variável foi privilegiada e outros fatores de risco e de proteção foram investigados em associação a esta.

A partir disso, o objetivo deste estudo foi identificar fatores de risco e de proteção no desenvolvimento de uma adolescente em situação de exploração sexual, analisando à luz desta abordagem, levando em conta a pessoa da adolescente entrevistada, os processos psicológicos e sociais nos quais esteve envolvida em sua trajetória, o momento atual de vida e sua história e os seus contextos de desenvolvimento (família, escola, lugar de residência, trabalho, rua, instituição que frequenta, sociedade, entre outros).

\section{Método}

\section{Delineamento}

Este estudo possui um delineamento de Estudo de Caso Único. De acordo com Yin (2005), este tipo de delineamento se propõe a investigar um 
fenômeno contemporâneo dentro de seu contexto real, de forma descritiva e exploratória. A escolha da participante e os critérios de seleção foram relacionados aos objetivos do estudo. A participante foi escolhida por estar envolvida em uma situação de exploração sexual há mais de seis meses, considerando esta atividade como seu trabalho e por se mostrar disponível para ser entrevistada. Esta disponibilidade pode ser compreendida como um pedido de ajuda diante da vivência a que está exposta - ainda que a mesma não tenha demonstrado, explicitamente, seu desconforto com a mesma. Trata-se de temática de estudo mobilizadora para todos os envolvidos na compreensão do fenômeno (vítima, instituição e pesquisadores). O teor do estudo, por seu caráter sistemático e rigoroso, pode transmitir uma idéia de frieza. Todavia, a equipe de pesquisa não perdeu de vista a delicadeza do tema, bem como a dificuldade de se aproximar da vivência genuína da jovem. De fato, era o único caso de exploração sexual na instituição abordada no período da pesquisa e que concordou imediatamente com a realização da mesma. Sua ênfase à atividade de exploração sexual como um trabalho, que auxiliava na sobrevivência, remuneração pessoal e identidade profissional, determinou o foco deste estudo.

O delineamento de estudo de caso proposto por Yin (2005) envolveu cinco componentes interligados: 1) as questões de pesquisa; 2) as proposições; 3) a(s) unidade(s) de análise; 4) a lógica que vincula os dados às proposições; e, 5) os critérios de interpretação dos dados. As questões de pesquisa estavam relacionadas aos fatores de risco e de proteção relacionados à exploração sexual de uma adolescente. As proposições consistiram em hipóteses teóricas do estudo que orientou os pesquisadores, que visavam a identificar tais fatores como influências no desenvolvimento da adolescente, com esta história de vida e no seu contexto de desenvolvimento. A unidade de análise baseou-se na fonte de informações dadas pela adolescente sobre sua vida e a exploração sexual. O quarto componente relacionou-se diretamente com a ênfase dada pela adolescente à atividade de exploração sexual como um trabalho, que auxiliava na sobrevivência, remuneração pessoal, identidade profissional e auxílio à sua família. O quinto componente desse delineamento - critério de interpretação dos dados - baseou-se na análise segundo a abordagem bioecológica do desenvolvimento humano. Estes passos basearam-se nas ideias de Yin (2005) de que a análise de dados pode ser baseada em: 1) proposições teóricas e 2) descrição do caso.

A principal questão de pesquisa consistiu em identificar e caracterizar um caso de exploração sexual de uma adolescente de 14 anos de idade. Foram investigadas características biosociodemográficas (idade, escolaridade, composição familiar, moradia) e questões abertas sobre a relação da adolescente com a família, a experiência com a atividade de exploração, com o seu corpo, com a comunidade onde vive, e projetos de futuro. Dessas questões gerais, emergiu, durante a própria entrevista, outra questão específica: a atividade de exploração sexual era considerada como um trabalho, que auxiliava na sobrevivência, remuneração pessoal e identidade profissional e pessoal. As proposições teóricas que orientaram a análise desta questão específica foram duas a priori (1 e 2) e uma a posteriori (3): 1) A exploração sexual é um fator de risco em si mesmo para o desenvolvimento humano, sendo considerado um abuso sexual e um evento violento e traumático. 2) A exploração sexual é uma atividade remunerada que pode ser definida como um trabalho (ainda que forçado, ilegal e criminalizado). 3) $\bigcirc$ trabalho é uma atividade que auxilia na sobrevivência pessoal e no auxílio à família, tem influência na identidade profissional e pessoal. A unidade de análise principal desse estudo, portanto, foi o caso de uma adolescente de quatorze anos de idade que vive na condição de exploração sexual e que a relata como um trabalho. A análise de dados baseia-se na descrição e discussão do caso, com base nas proposições teóricas propostas a priori e a posteriori.

O método de estudo de caso único propiciou uma análise abrangente da variável exploração sexual como atividade laboral, levando em conta os contextos de trauma e violência associados a ela. Devido às características específicas do objeto de estudo e pela necessidade de aproximação 
da pesquisadora com a participante no contexto institucional, foi realizada inserção ecológica, com base nos princípios da abordagem bioecológica do desenvolvimento humano (Cecconello \& Koller, 2003; Eschiletti, Paula, Moura, Poletto \& Koller, 2008).

\section{Relato de Caso}

A participante será chamada ficticiamente de Manuela. Ela tem atualmente 14 anos, é parda e nasceu em uma cidade do Nordeste do Brasil, onde viveu com a família até o último aniversário, portanto recentemente. Filha de pai e mãe agricultores analfabetos, ela frequentou a escola de maneira irregular, saindo definitivamente na quarta série do ensino fundamental. Desde muito cedo ajudava a família na lavoura de cana-de-açúcar junto com mais três irmãos (todos meninos).

De família patriarcal machista, a infância e a entrada na puberdade "foi conturbada". Relata medos e total desconhecimento de questões sexuais naquela época. Muito cedo (não lembra quando), começou a ser assediada por um vizinho (cerca de 30 anos) e isto era motivo de confusões com os irmãos mais velhos.

Relata ter sofrido assédio sexual com ofensas e provocações por parte de amigos, vizinhos e até dos irmãos. Diz ter sido "tocada e beijada à força por estes”. Aos 13 anos, foi forçada pela família a fazer sexo com um vizinho de 18 anos (amigo do irmão), provavelmente, segundo informa "como pagamento por uma briga de vizinhos".

Continuou fazendo sexo forçado com o vizinho até que engravidou e sofreu aborto. Com todo episódio vindo à tona, o clima familiar piorou e relata ter sido expulsa da família pelo pai que lhe "chamava com palavras de baixo calão". O pai a ameaçava de expulsão de casa, até que Manuela encontrou uma amiga disposta a fugir da cidade com ela.

Ainda aos 14 anos, fugiu para outro estado e foi abrigar-se na moradia de uma tia da amiga. Vive, atualmente, em uma casa com esta mulher e mais três jovens meninas (uma menor e duas maiores de 18 anos), todas oriundas de seu estado natal. Segundo relata, atendem os "clientes nesta casa".
Esta condição de vida foi denunciada, pela suspeita de vizinhos de que a casa seja um lugar de exploração sexual e prostituição. $\mathrm{O}$ caso está sob acompanhamento do Juizado da Infância de da Juventude e do Conselho Tutelar e Manuela está em atendimento psicológico numa instituição. Por não admitir fazer sexo forçado e "proteger" a provável cafetina, muitas vezes negando sua função de aliciadora, o caso ainda não chegou à intervenção judicial contra esta mulher.

Durante a entrevista da pesquisa revelou claramente a situação de exploração sexual. Diz que faz "sexo para sobreviver, que este é o seu trabalho e porque quer e gosta desta vida". Considera que os homens com quem faz sexo são como namorados. Não se denomina como "uma prostituta só por receber 'agrados ' dos homens com quem 'fica'". Tem alguns rapazes que são clientes freqüentes e, por isso, considera-os como "ficantes. Diz que "prostituta é quem vai rodar a bolsinha na calçada". Descreve a si mesma como sendo "uma menina bonita e cobiçada e diz que se diverte com isso". Diz que "nunca é forçada a fazer sexo com quem não quer". Não acredita que vai voltar para escola ou arrumar outro trabalho. Diz que seu futuro é "ficar nesta casa", e aponta o turismo sexual em seu estado natal, como uma possibilidade de ganhar mais dinheiro. Mais detalhes sobre o caso estão apresentados na seção de Resultados.

\section{Procedimentos e Instrumentos}

A instituição que atende adolescentes exploradas sexualmente e que presta serviços foi contatada. Os objetivos e o procedimento da pesquisa foram apresentados para o responsável e solicitado a sua participação. O Termo de Concordância da Instituição foi assinado. Para a participante, foi a apresentado o Termo de Consentimento Livre e Esclarecido. A pesquisa seguiu as determinações do Conselho Federal de Psicologia, Resolução n.16/2000 (2000) e a Resolução n.196 (1996) do Conselho Nacional de Saúde, e ECA (1990). A pesquisa foi aprovada pelo Comitê de Ética em Pesquisa do Grupo Hospitalar Conceição de Porto 
Alegre, e está registrada no SISNEP sob o protocolo n. 0142.1.164.000-08.

A inserção ecológica foi iniciada na instituição, a partir de visitas para ambientação com o contexto, conhecimento dos profissionais envolvidos (principalmente da Psicologia) e da participante. Nesta fase, conhecer a rotina da instituição e estabelecer conversas informais foi importante para iniciar a vinculação da pesquisadora com a participante. A entrevista semi-estruturada foi composta de questões sobre a caracterização biosociodemográfica (idade, escolaridade, composição familiar, moradia) e questões abertas sobre a relação da adolescente com a família, a experiência com a atividade de exploração, com o seu corpo, com a comunidade onde vive e projetos de futuro. Foi possível observar que o roteiro de entrevista não possui nenhuma questão específica relacionada ao entendimento de exploração sexual como um trabalho. Ocorre que, a fim de não induzir a participante a esta compreensão, optou-se pela não elaboração de questões diretas, de forma que o conteúdo emergisse espontaneamente no decorrer da entrevista. Pelas respostas da participante, houve interesse em explorar mais a questão relacionada à exploração sexual como atividade laboral e isto foi realizado com uma pergunta aberta: Fale mais sobre esta sua visão de que a sua atividade sexual é o seu trabalho. A pesquisadora utilizou um diário de campo, no qual fez registros sobre o andamento da pesquisa. Os resultados serão devolvidos de forma direta para a instituição. $O$ objetivo desta atividade é de que os resultados possam contribuir com o trabalho de profissionais que lidam diretamente no atendimento de outras adolescentes envolvidas com a prática da exploração sexual.

\section{Resultados e Discussão}

Os resultados estão apresentados e discutidos a seguir e visam a responder à principal questão de pesquisa, que consistiu em identificar e caracterizar um caso de exploração sexual de uma adolescente de 14 anos de idade. A Tabela 1 apresenta a descrição biosociodemográfica do caso, com os aspectos investigados na entrevista sobre a sua visão do próprio corpo e do gênero, as proposições abordadas e exemplos de vinhetas das respostas da adolescente.

TABELA 1

Dados Biossociodemográficos, Visão sobre o Próprio Corpo e sobre o Gênero da Participante do Estudo

\begin{tabular}{|c|c|c|}
\hline $\begin{array}{l}\text { Aspecto } \\
\text { investigado }\end{array}$ & Proposição & Resultado \\
\hline \multirow{8}{*}{$\begin{array}{l}\text { Dados } \\
\text { bio } \\
\text { sócio } \\
\text { demográ- } \\
\text { ficos }\end{array}$} & Escolaridade & $\begin{array}{l}\text { Quarta série do ensi- } \\
\text { no fundamental }\end{array}$ \\
\hline & Idade & 14 anos completos \\
\hline & $\begin{array}{l}\text { Com quem } \\
\text { mora }\end{array}$ & $\begin{array}{l}\text { Com uma mulher adul- } \\
\text { ta, uma adolescente e } \\
\text { duas jovens de seu es- } \\
\text { tado natal. Nenhuma } \\
\text { delas tem parentesco } \\
\text { com Manuela }\end{array}$ \\
\hline & $\begin{array}{l}\text { Composição da } \\
\text { família }\end{array}$ & $\begin{array}{l}\text { Pai, mãe e três irmãos } \\
\text { do sexo masculino }\end{array}$ \\
\hline & $\begin{array}{l}\text { Trabalho do pai } \\
\text { e/ou da mãe }\end{array}$ & Agricultores \\
\hline & Estado civil & Solteira \\
\hline & $\begin{array}{l}\text { Filhos(as) } \\
\text { vivos(as) }\end{array}$ & Nenhum \\
\hline & Gravidez & $\begin{array}{l}\text { "Uma gravidez e um } \\
\text { aborto antes dos } 14 \\
\text { anos de idade. O pai } \\
\text { era um vizinho de } 18 \\
\text { anos." }\end{array}$ \\
\hline \multirow{3}{*}{ Corpo } & $\begin{array}{l}\text { Como vê o seu } \\
\text { corpo }\end{array}$ & "Uma menina bonita" \\
\hline & $\begin{array}{l}\text { O que sente so- } \\
\text { bre seu corpo }\end{array}$ & $\begin{array}{l}\text { Saudável } \\
\text { "Está sempre procu- } \\
\text { rando estar atrativa e } \\
\text { se cuidar" }\end{array}$ \\
\hline & $\begin{array}{l}\text { Como se previ- } \\
\text { ne das DSTs e } \\
\text { AIDS }\end{array}$ & $\begin{array}{l}\text { "Uso camisinha de } \\
\text { vez em quando" }\end{array}$ \\
\hline Gênero & Ser mulher & "Ser cobiçada" \\
\hline
\end{tabular}

Fonte: elaboração própria

A Tabela 2 apresenta a sua visão sobre a família de origem e sua infância e adolescência. 
TABELA 2

Dados sobre a Família e a Infância e Adolescência da Participante do Estudo

\begin{tabular}{|c|c|c|}
\hline \multirow[b]{2}{*}{ Família } & $\begin{array}{l}\text { Como é a sua } \\
\text { família? }\end{array}$ & "Machista" \\
\hline & $\begin{array}{l}\text { Como é a } \\
\text { sua relação } \\
\text { com ela? }\end{array}$ & $\begin{array}{l}\text { "Fugi de casa aos } 14 \text { anos e } \\
\text { não volto para casa do meu } \\
\text { pai de jeito nenhum. Pra } \\
\text { quê? Pra apanhar? Ir pra } \\
\text { roça? Já disse ao juiz, se eu } \\
\text { for eu fujo de novo. Meu pai } \\
\text { já disse também que não me } \\
\text { quer mais. O que eu vou fa- } \\
\text { zer? Tá bom aqui mesmo" }\end{array}$ \\
\hline \multirow[t]{2}{*}{$\begin{array}{l}\text { Infância } \\
\text { e adoles- } \\
\text { cência }\end{array}$} & $\begin{array}{l}\text { Como foi a } \\
\text { sua infância? }\end{array}$ & $\begin{array}{l}\text { "Foi conturbada". Sofreu } \\
\text { assédio sexual com ofensas } \\
\text { e provocações por parte de } \\
\text { amigos, vizinhos e até dos } \\
\text { irmãos. Foi tocada e beija- } \\
\text { da à força por estes. Aos } 13 \\
\text { anos foi forçada pela família, } \\
\text { a fazer sexo com um vizin- } \\
\text { ho de } 18 \text { anos (amigo do } \\
\text { irmão), "como pagamento } \\
\text { por uma briga de vizinhos". } \\
\text { Continuou fazendo sexo for- } \\
\text { çado com o vizinho até que } \\
\text { engravidou e sofreu aborto. } \\
\text { Com todo episódio vindo à } \\
\text { tona, o clima familiar piorou } \\
\text { e relata ter sido expulsa de } \\
\text { casa pelo pai que lhe "cha- } \\
\text { mava com palavras de baixo } \\
\text { calão". O pai a ameaçava } \\
\text { de expulsão de casa, até que } \\
\text { Manuela encontrou uma } \\
\text { amiga disposta a fugir da } \\
\text { cidade com ela. }\end{array}$ \\
\hline & $\begin{array}{l}\text { Como foi/ } \\
\text { está sendo a } \\
\text { sua adoles- } \\
\text { cência? }\end{array}$ & $\begin{array}{l}\text { "Podia ser melhor, mas a } \\
\text { culpa não é da minha tia, a } \\
\text { culpa toda é do meu pai. Ela } \\
\text { só quer me ajudar" }\end{array}$ \\
\hline
\end{tabular}

Fonte: elaboração própria

A Tabela 3 apresenta a percepção sobre si mesma e dos outros sobre si da participante do estudo. A participante dá indícios na percepção da sua atividade como um trabalho, e quer ser reconhe- cida como pessoa prestadora deste serviço como qualquer outro.

\section{TABELA 3}

Percepção sobre Si Mesma e dos Outros sobre Si da Participante do Estudo

\begin{tabular}{|c|c|c|}
\hline \multirow{3}{*}{$\begin{array}{l}\text { Percepção } \\
\text { sobre si e } \\
\text { dos outros }\end{array}$} & $\begin{array}{l}\text { O que as pessoas } \\
\text { pensam sobre } \\
\text { você? }\end{array}$ & $\begin{array}{l}\text { "Não me interessa, } \\
\text { sou assim e pronto" }\end{array}$ \\
\hline & $\begin{array}{l}\text { Como você gosta- } \\
\text { ria que as pessoas } \\
\text { pensassem sobre } \\
\text { si? }\end{array}$ & $\begin{array}{l}\text { "Como uma pessoa } \\
\text { qualquer que tem seu } \\
\text { trabalho e não inco- } \\
\text { moda ninguém" }\end{array}$ \\
\hline & $\begin{array}{l}\text { O que você mu- } \\
\text { daria na vida sua } \\
\text { vida hoje? }\end{array}$ & $\begin{array}{l}\text { "Teria saído de casa } \\
\text { mais cedo" }\end{array}$ \\
\hline $\begin{array}{l}\text { Projeto de } \\
\text { vida }\end{array}$ & $\begin{array}{l}\text { Quais planos para } \\
\text { o futuro? }\end{array}$ & $\begin{array}{l}\text { "Sonho? Casar mes- } \\
\text { mo, né?" }\end{array}$ \\
\hline
\end{tabular}

Fonte: elaboração própria

A Tabela 4 mostra as respostas da adolescente com relação à exploração sexual. Destacou-se a definição da atividade de exploração sexual como um trabalho, que auxiliava na sobrevivência, remuneração e independência da adolescente. A exploração sexual mostrou-se como um fator de risco em si mesmo para o desenvolvimento humano, sendo considerado um abuso sexual e um evento violento e traumático, conforme proposição teórica expressa a priori para análise neste estudo. Por outro lado, a partir da percepção da garota, a atividade de exploração sexual definida como um trabalho - que lhe proporciona sobrevivência e autonomia - pode estar sendo avaliada por ela como fator protetivo. Nesse sentido, a proposição teórica a posteriori também confirmou presença nestes dados, ou seja, a exploração sexual apareceu como uma atividade remunerada, que foi definida pela participante como um trabalho. $\mathrm{O}$ trabalho para ela, segundo a proposição teórica, foi descrito como uma atividade que auxiliava na sobrevivência pessoal. $O$ trabalho para ela tem influência na identidade profissional e pessoal. 


\section{TABELA 4}

Visão sobre a Exploração Sexual da Participante do Estudo

\begin{tabular}{|c|c|c|}
\hline & $\begin{array}{l}\text { Com qual idade } \\
\text { começou? }\end{array}$ & $\begin{array}{l}\text { Não sabe precisar, mas "com } 12 \\
\text { anos já tinha atividade sexual em } \\
\text { troca de favores e presentes, com } \\
\text { os vizinhos, mas "forçada pelos } \\
\text { irmãos" }\end{array}$ \\
\hline & $\begin{array}{l}\text { O que pensa } \\
\text { sobre isto? }\end{array}$ & $\begin{array}{l}\text { "É minha forma de sobreviver, } \\
\text { de ajudar na casa que vivo, de } \\
\text { comprar o que preciso. Não vou } \\
\text { ter outro trabalho, isto é o que } \\
\text { sou, este é meu trabalho" }\end{array}$ \\
\hline & $\begin{array}{l}\text { O que pensam } \\
\text { sobre os ho- } \\
\text { mens/mulheres } \\
\text { clientes? }\end{array}$ & "São meus ficantes" \\
\hline & $\begin{array}{l}\text { O que é para } \\
\text { você um bom } \\
\text { cliente ou mau } \\
\text { cliente? }\end{array}$ & $\begin{array}{l}\text { "Bons os que pagam, ruins os } \\
\text { que não pagam" }\end{array}$ \\
\hline & $\begin{array}{l}\text { Como você faz } \\
\text { o programa? } \\
\text { Sozinha? Com } \\
\text { outras? }\end{array}$ & $\begin{array}{l}\text { "Na minha casa e busco eles no } \\
\text { bar e no posto de gasolina, vou } \\
\text { lá com as amigas" }\end{array}$ \\
\hline & $\begin{array}{l}\text { Como estabele- } \\
\text { ce o preço? }\end{array}$ & $\begin{array}{l}\text { "Eu ganho uns R } \$ 200,00 . E ́ \\
\text { pouco. Mas dizem que é porque } \\
\text { o povo aqui é pobre, paga pou- } \\
\text { co, tem pouco homem nessa } \\
\text { cidade. Dizem que bom é em } \\
\text { Aracaju, Maceió, Salvador, mas } \\
\text { é mais arriscado também. Aqui } \\
\text { todo mundo já me conhece" }\end{array}$ \\
\hline & $\begin{array}{l}\text { Há prazer se- } \\
\text { xual enquanto } \\
\text { faz o programa? }\end{array}$ & $\begin{array}{l}\text { "Às vezes eu sinto prazer, ou- } \\
\text { tras vezes eu tenho medo, nojo. } \\
\text { Depende do homem. Mas vou } \\
\text { dizer que é ruim não fazer isso" }\end{array}$ \\
\hline & $\begin{array}{l}\text { O que mudou } \\
\text { na sua vida } \\
\text { depois de ter } \\
\text { entrado na ex- } \\
\text { ploração? }\end{array}$ & $\begin{array}{l}\text { "Sou independente, não sou } \\
\text { prostituta, porque não roda a } \\
\text { bolsinha na calçada". "Faço } \\
\text { sexo para sobreviver, que este é } \\
\text { o meu trabalho e porque quero } \\
\text { e gosto desta vida" }\end{array}$ \\
\hline & $\begin{array}{l}\text { A família sabe? } \\
\text { Como lida? }\end{array}$ & "Não sabem de mim" \\
\hline
\end{tabular}

Fonte: elaboração própria
A Tabela 5 inclui os fatores de risco presentes na vida pregressa e atual da adolescente participante do estudo.

\section{TABELA 5}

Fatores de Risco Presentes na Vida Pregressa e Atual da Adolescente Participante do Estudo

Tem apenas 14 anos e já está exposta à exploração sexual há bastante tempo

Escolaridade baixa e fora da série esperada para sua idade

Infância na zona rural, sem conhecer aspectos $\approx$ relacionados à vida em cidades maiores e cen$\frac{\pi}{5}$ tros urbanos

Desconhecimento de aspectos da sexualidade : mente ditas

Assédio e atividade sexual com estranhos e O familiares

Fo Foi forçada a manter relações sexuais intrafami-

安 liares e extrafamiliares

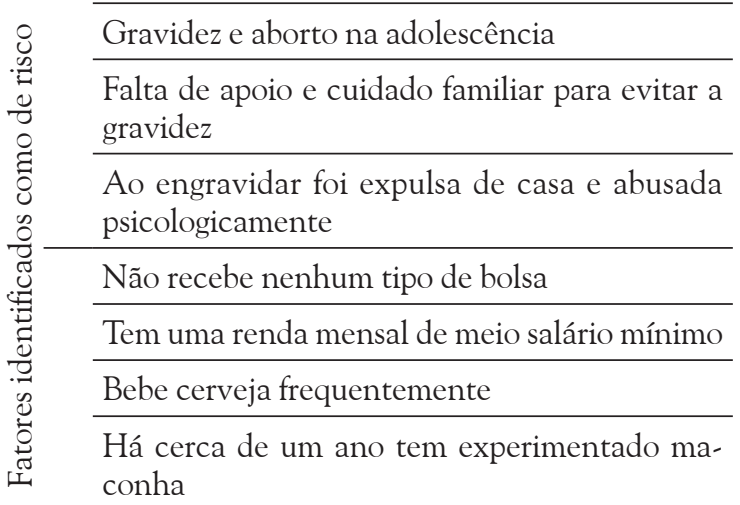

Usa camisinha sem consistência

Faz sexo por dinheiro ou presentes mais de duas I vezes por semana há mais de um ano

$\approx$ Usa a casa onde vive para suas atividades sexuais

Frequenta um bar e um posto de gasolina para $\stackrel{5}{s}$ encontrar com quem fazer sexo

Foi convidada a fazer sexo pago por amigas e pela dona da casa onde vive

Vive em um prostíbulo

Encara a atividade de exploração sexual como uma atividade laboral, identifica-se como profissional adolescente do sexo

Não visa a buscar outra atividade laboral

Fonte: elaboração própria 
Quando Manuela relata que foi abusada sexualmente desde a pré-adolescência, com consentimento da família, identifica-se, para além da permissão dos pais e irmãos, uma marca na construção da sua identidade. De alguma forma, a jovem é reconhecida como integrante que auxilia nas dificuldades domésticas através do oferecimento de seu corpo (Amazarray \& Koller, 1998). Registrase, aí, o quanto o ser humano se constrói a partir das ações que realiza - ainda que estas possuam caráter perverso e desprotegido. Esta marca ficou de tal maneira registrada em sua vida que, mesmo após sair de casa e das desavenças vividas neste local, segue vendendo seu corpo (De Antoni, 2000; Libório, 2005). Além disso, justifica esta situação como a execução de uma atividade laboral, que lhe permite sobreviver e ter independência.

A Tabela 6 inclui os fatores de proteção presentes na vida pregressa e atual da adolescente participante do estudo.

\section{TABELA 6}

Fatores de Proteção Presentes na Vida Pregressa e Atual da Adolescente Participante do Estudo

\begin{tabular}{|c|c|c|}
\hline \multirow{10}{*}{ 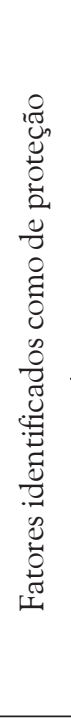 } & \multirow{6}{*}{ 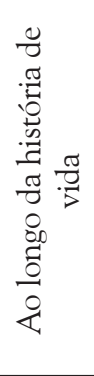 } & Não relata doenças crônicas \\
\hline & & Foi à escola \\
\hline & & Teve uma família \\
\hline & & Teve algumas amigas \\
\hline & & Tem boa saúde física \\
\hline & & Ter saído de casa \\
\hline & \multirow{4}{*}{ 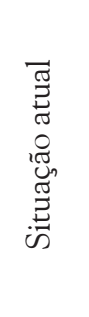 } & $\begin{array}{l}\text { Sente-se acolhida e cuidada pelas pes- } \\
\text { soas com quem vive }\end{array}$ \\
\hline & & $\begin{array}{l}\text { Seus clientes têm alguma relação com } \\
\text { ela, pois os vê como "ficantes" }\end{array}$ \\
\hline & & Participa das atividades da instituição \\
\hline & & Recebe atendimento psicológico \\
\hline
\end{tabular}

Fonte: elaboração própria

A violência doméstica ou familiar aparece nitidamente, neste caso, como fator de risco para a exploração sexual. A adolescente fugiu para outro contexto que também apresenta risco, mas segue a atividade sexual como se fosse o que melhor sabe executar. A exploração sexual consiste em uma estratégia de sobrevivência e de identidade pessoal. A violência social ou da comunidade parece atenuada e não criticada, frente à violência forçada pela família de origem. De acordo com DutraThomé (2009) jovens trabalhadores sofrem mais violência doméstica e na comunidade e possuem maior frequencia de uso de drogas quando comparados jovens não trabalhadores, neste último caso, provavelmente por obterem recursos para adquiri-las. O alto índice de uso de drogas (álcool, maconha, crack ou cocaína) tem sido identificado como fator de risco associado pela literatura com a exploração sexual (Libório, 2005; Serpa, 2009).

Adolescentes expostos à exploração sexual devem ser tratados como vítimas e receber apoio e assistência do Estado. Não podem ser tratados como criminosos e merecem atenção e proteção das suas famílias e comunidades (Pinheiro, 2009). A saída da casa, para obtenção de sustento pessoal ou para auxiliar à família, está associada à segurança das crianças e dos adolescentes - que geralmente saem impelidas por uma situação limite de violências, abusos e maus tratos, associada à questões econômicas envolvidas na atividade de exploração. Neste caso, Manuela não tinha segurança nem mesmo em casa ou na sua comunidade de origem, o que provavelmente a leva a exigir menos ainda nos novos contextos nos quais ela se insere. Nesse contexto, a exploração sexual, enquanto atividade laboral degradante, aproxima-se da própria etimologia da palavra trabalho, originada do termo tripalium - referente a instrumento agrícola utilizado para tortura (limitador do ser humano) e, ao mesmo tempo, para cultura de cereais (transformador da natureza) (Albornoz, 1986; Borges \& Argolo, 2002; Jacques, 2002; Mendes \& Morone, 2002; Nardi, 2006). Esta associação se estabelece pelo fato de que a venda do corpo torna-se uma alternativa de trabalho e única fonte de sustento, caracterizada pela perversidade e violação de direitos.

Ainda que exposta a uma forma de trabalho degradante, Manuela parece não possuir noção da violação de seus direitos e nem mesmo com a participação na instituição luta por eles. A residência 
em uma casa denunciada como prostíbulo, a falta de apoio das instâncias reguladoras de seus direitos e de segurança pessoal, não são questionadas por ela. Por definição, segundo Pinheiro (2009), os entornos de crianças e adolescentes que permitem o trabalho não favorecem a garantia de seus direitos e são omissos na proteção contra a violência física, psicológica e sexual, especialmente no caso de exploração.

O propósito principal das campanhas e dos programas pela erradicação do trabalho infantojuvenil e contra a violência tem sido a retirada de crianças/adolescentes de contextos que prejudicam o seu desenvolvimento ao longo do ciclo vital. No caso da exploração sexual, este foco deveria ser ainda mais nítido, especialmente pela junção de ambos os riscos (trabalho infanto-juvenil e violência) e por favorecer uma economia de mercado perversa. No entanto, a inibição e a extinção destas condições de vida não têm sido efetivas. Ao contrário, a retirada de crianças e adolescentes destes contextos, parece ser seguida de uma enxurrada de novos personagens que ocupam seu lugar. Além disso, a configuração atual do mercado de trabalho caracteriza-se por relações laborais fragilizadas diante do desemprego, escassas políticas de geração de renda e mecanismos insuficientes de inserção dos jovens no mercado de trabalho (Lima \& Minayo-Gomes, 2003). O mercado da exploração sexual - que só ocorre porque há clientela - tornase, portanto, alternativa de sobrevivência e tem nutrido uma crescente indústria de pessoas na crise econômica (Cerqueira-Santos, Morais, Moura $\&$ Koller, 2008; Pinheiro, 2009). Este panorama evidenciou-se no depoimento da adolescente, ao mencionar sua relação com a clientela a partir do serviço que presta: "Bons os que pagam, ruins os que não pagam"; "Na minha casa e busco eles no bar e no posto de gasolina, vou lá com as amigas"; "Eu ganho uns $R \$ 200,00$. É pouco. Mas dizem que é porque o povo aqui é pobre, paga pouco, tem pouco homem nessa cidade".

A participação no cotidiano de atividades de exploração sexual afasta, ainda mais, as crianças e os adolescentes da escolarização e de uma educação de qualidade, criando um ciclo maléfico que afasta as possibilidades de obtenção de outras atividades laborais e projetos de vida. Manuela já apresentava dificuldades de acompanhar sua escola, de acordo com sua idade, tendo sido afastada várias vezes para o trabalho no corte da cana-de-açúcar. Suas possíveis dificuldades de aprendizagem, fruto de sua história de abuso sexual na família e na comunidade, provavelmente poderiam estar - ainda que não relatados - relacionadas à ansiedade e estados depressivos, expressões previsíveis em vítimas de abuso sexual (Habigzang, Azevedo, Koller \& Machado, 2006; Habigzang, Hatzenberger, Dala Corte, Stroeher \& Koller, 2008).

A exploração sexual, além de gerar sintomas psicopatológicos, poderia expor a saúde física e moral de Manuela (Morais, 2005). Pinheiro (2009) apontou que as crianças e adolescentes envolvidos na exploração sexual, em geral, têm condenado esta forma de sobreviver. Classificam esta atividade como criminosa e diferenciada de outros tipos de trabalho (Pinheiro, 2009). Este não é o caso da participante deste estudo, uma vez que, mesmo planejando no futuro casar e ter uma família, identificou-se como uma profissional do sexo. Segundo ela, esta atividade ocupacional the permite sobreviver, além de ser aquilo que diz saber fazer. Esta descrição, todavia, não descarta o possível sofrimento implícito presente no caso. Manuela, por exemplo, denomina seus clientes como "ficantes", uma possível forma de amenizar o caráter mercadológico da relação estabelecida com eles. Além disso, descreve em duas passagens "Meu pai já disse também que não me quer mais. O que eu vou fazer? Tá bom aqui mesmo" e, ao relatar a relação com a possível cafetina: "Podia ser melhor, mas a culpa não é da minha tia, a culpa toda é do meu pai. Ela só quer me ajudar". Estas frases expressam o sofrimento de Manuela perante a violência doméstica a que foi exposta e o envolvimento com a exploração sexual como uma opção de trabalho relacionada com a falta de alternativas mais saudáveis.

Um estudo em treze países sobre a exploração sexual na infância e na adolescência sugere que esta condição está aumentando e as atividades criminosas associadas também, assim como o turismo sexual, a pornografia e os delitos relacionados 
à internet (UNICEF, 2004). As meninas têm sido mais frequentemente identificadas neste esquema de exploração, embora meninos também sejam envolvidos. A faixa de idade das meninas envolvidas em vários países deste relatório está entre os 12 e os 14 anos, como no caso deste estudo.

Um dos pontos preocupantes na colocação da entrevistada é, justamente, a não percepção da atividade que executa como uma exploração, ou seja, o não reconhecimento da sua situação de vítima. Sarriera, Silva, Kabbas e Lopes (2001) descreveram que as primeiras experiências laborais constituem a identidade dos jovens em formação, pois servem como um modelo de referência. A adolescente iniciou a execução desta atividade num momento frágil na construção de sua identidade, o que se destacou ao dizer "É minha forma de sobreviver, de ajuda na casa que vivo, de comprar o que preciso. Não vou ter outro trabalho. Isto é o que sou, este é o meu trabalho"; "Sou independente, não sou prostituta (...) Faço sexo para sobreviver, que este é o meu trabalho e porque quero e gosto desta vida". Nesse sentido, a exploração sexual naturalizou-se como elemento que lhe dá a oportunidade de sobreviver, ser autônoma e, até mesmo, de reconhecer a si mesma como um ser humano capaz de produzir alguma coisa e, a partir disso, ser reconhecida. De fato, a categoria trabalho, enquanto objeto de reflexão, o aponta como um elemento de integração social, fonte de auto-estima e de sentido para a vida das pessoas (Prieb, 2000). O trabalho é um fator contribuinte para o crescimento do indivíduo, de forma a incorporar sentimentos de auto-estima e realização a sua personalidade (Forastieri, 1997). Entretanto, a execução de uma forma de trabalho degradante, como a exposição à exploração sexual, distancia o indivíduo dos componentes geradores de saúde e desenvolvimento emocional, moral e cognitivo das pessoas, bem como para seu reconhecimento social (Filgueiras \& Hippert, 2002).

\section{Considerações Finais}

Vários fatores de risco presentes no caso de Manuela têm se repetido em estudos internacionais, como aponta a United Nations Secretary-General's
Study on Violence against Children (2005). Um fator de risco marcadamente presente em vários estudos, inclusive na América Latina, tem sido a violência intrafamiliar. A entrada na exploração sexual tem sido relacionada com o abandono e a estigmatização social das crianças e adolescentes (Pinheiro, 2009). Esta condição começa no próprio microssistema familiar e se alastra para outros contextos de desenvolvimento. Portanto, a vítima, em geral, abandona a escola e é excluída de grupos de iguais.

Outros contextos macrossistêmicos, também marcados pela pobreza e pela desigualdade social, mostram que meninas e meninos são envolvidos em exploração sexual como uma estratégia de sobrevivência, em troca de alimento, habitação, acolhida e drogas (Human Rights Watch, 2001). Diante da atual configuração do mercado de trabalho, caracterizada pela falta de instabilidade nos empregos, crescimento da informalidade e escassa abertura de novos postos de trabalho (Abramovay, Castro, Pinheiro, Lima \& Matinelli, 2002), estes adolescentes tornam-se vulneráveis à exposição a formas de trabalho degradantes, como no caso de Manuela. Embora em muitos destes relatos haja associação com tortura e golpes violentos, estes não aparecem no relato de Manuela, que se limita a comentar que, às vezes, tem nojo, mas nem isto a limita.

Eventos e resultados negativos ao longo do desenvolvimento já existiam anteriormente à vinda para a casa onde vive atualmente e para as atividades de exploração sexual. A vinculação e a identificação com o papel de uma profissional foi processual. Os vínculos familiares eram frágeis e quase inexistentes, assim como o relacionamento com a escola e com a comunidade de origem. Esta lacuna facilitou a inserção da adolescente na rede de exploração sexual, expondo-a a uma atividade de elevado risco para sua saúde física e mental, privando-a do seu direito a formas protegidas de trabalho. Trata-se de mais uma das diferentes trajetórias de vinculação com a exploração sexual, já identificada por Morais (2009), as quais só podem ser entendidas se devidamente contextualizadas, a partir das características individuais e da rede de apoio de cada indivíduo. 
O não reconhecimento da condição de vítima por parte da própria participante é um elemento crucial para entender a sua relação com a atividade laboral. Imaginar que a atividade de ESCA é uma "alternativa" de sobrevivência minimiza a condição degradante e a própria noção de exploração. Este não reconhecimento está claramente ligado à dificuldade de intervenção em casos como o aqui analisado. Instituições de atendimento, profissionais e pesquisadores têm como tarefa desvelar os motivos primários do envolvimento e manutenção de meninas e meninos na situação de ESCA, recolocandoos, a todo tempo, no local de vítimas, explorados e retomando a discussão de que são indivíduos em formação - os quais precisam de oportunidades de desenvolvimento saudável.

A exploração sexual gera prejuízo para a qualidade de vida dos adolescentes envolvidos. Ocorre de forma processual (Libório, 2004) e carece de atenção da rede de proteção, dos programas voltados para essa realidade e de pesquisas psicológicas e sociais sobre a exploração sexual (Dos Santos, 2004). Uma análise sob o prisma da abordagem bioecológica do desenvolvimento humano pode ser uma alternativa teórico-metodológica que abarque a complexidade do fenômeno.

A promoção do trabalho descente - produtivo, remunerado justamente, que promove segurança e proteção social para as famílias, fonte de melhores perspectivas para o desenvolvimento das pessoas e sua integração social (OIT, 2002; Somavia, 2001) - parece estar distante da realidade descrita neste estudo. A adolescente participante não possui maturidade física, mental e moral para a realização da atividade que executa, elementos necessários para uma vivência profissional repleta de significados, sentido e satisfação pessoal (Amazarray et al., 2007). Ademais, as limitações do estudo não permitiram o estabelecimento do contato com a experiência genuína de sofrimento da participante, todavia, ficaram evidentes os diversos fatores de risco aos quais Manuela encontra-se exposta. Este contexto de atividade laboral degradante e violador de direitos explicita a necessidade do fenômeno da exploração sexual ser analisado, também, através de lente da Psicologia do Trabalho.
Diante de um mercado profissional fragilizado, o envolvimento com a exploração sexual torna-se alternativa de sobrevivência e elemento constituinte da relação do indivíduo com o mundo.

\section{Referências}

Abramovay, M., Castro, M. J., Pinheiro, L. C., Lima, F. S. \& Matinelli, C. C. (2002). Juventude, violência e vulnerabilidade social na América Latina: desafios para políticas públicas. Brasília: UNESCO/BID.

Albornoz, S. (1986). O que é trabalho? (6ª ed.). São Paulo: Brasiliense.

Amazarray, M. \& Koller, S. (1998). Alguns aspectos observados no desenvolvimento de crianças vítimas de abuso sexual. Psicologia Reflexão e Crítica, 11 (3), 546-555.

Amazarray, M. R., Dutra-Thomé, L., Poletto, M. \& Koller, S. (2007). Perspectivas acerca do trabalho infanto-juvenil: ideologias, subjetividade e saúde do trabalhador. Laboreal, 3 (2), 22-28.

Assunção, A. A. \& Dias, E. C. (2002). Trabalho precoce: possíveis efeitos sobre o desenvolvimento das crianças e adolescentes. Revista Devir: Esquizoanálise e seus Encontros, 1 (2), 39-60.

Barros, R. P. de \& Santos, E. C. (1996). Conseqüências de longo prazo do trabalho precoce. In A. Fausto \& R. Cervini (Eds.), O trabalho e a rua: Crianças e adolescentes no Brasil urbano dos anos 80 (2ª ed., pp. 56-61). São Paulo: Cortez.

Borges, L. O. B. \& Argolo, J. C. T. (2002). Estratégias Organizacionais na Promoção da Saúde mental do Individuo podem ser eficazes. In M. G. Jacques \& W. Codo (Eds.), Saúde Mental e Trabalho: leituras (pp. 271-295). Petrópolis, RJ: Vozes.

Brasil, Lei Federal 8069/1990. Estatuto da Criança e do Adolescente, Brasília, DF.

Brasil, Resolução no 016/2000 [Conselho Federal de Psicologia]. 20 de dezembro de 2000. Brasília, DF.

Brasil, Resolução n⿳0196/1996 [Conselho Nacional de Saúde]. 16 de outubro de 1996. Brasília, DF.

Bronfenbrenner, U. (1996). A ecologia do desenvolvimento humano: experimentos naturais e planejados. Porto Alegre: Artes Médicas. (Originalmente publicado em 1979) 
Bronfenbrenner, U. \& Morris, P. (1998). The ecology of developmental processes. In W. Damon (Ed.), Handbook of child psychology (Vol. 1, pp. 993-1027). New York: John Wiley \& Sons, Inc.

Cecconello, A. M. (2003). Resiliência e vulnerabilidade em família em situação de risco. Tese de Doutorado não publicada, Curso de Pós-Graduação em Psicologia, Universidade Federal do Rio Grande do Sul, Porto Alegre, RS. Disponível em http://hdl. handle.net/10183/2641

Cecconello, A. M. \& Koller, S. H. (2003). Inserção ecológica na comunidade: uma proposta metodológica para o estudo de famílias em situação de risco. Psicologia: Reflexão e Crítica, 16 (3), 515-524.

Cerqueira-Santos, E., Morais, N. A., Moura, A. \& Koller, S. (2008). Exploração sexual de crianças e adolescentes: uma análise comparativa entre clientes e não clientes do comércio sexual. Psicologia: Reflexão e Crítica, 21 (3), 446-454.

De Antoni, C. (2000). Vulnerabilidade e resiliência familiar na visão de adolescentes maltratadas. Dissertação de mestrado não publicada, Curso de PósGraduação em Psicologia, Universidade Federal do Rio Grande do Sul, Porto Alegre, RS. Disponível em http://hdl.handle.net/10183/2116

Dos Santos, B. R. (2004). Contribuições para um balanço das campanhas de combate ao abuso e exploração sexual de crianças e adolescente no Brasil. In R. M. C. Libório \& S. M. G. Sousa (Orgs.), Exploração sexual de crianças e adolescentes no Brasil: reflexões teóricas, relatos de pesquisa e intervenções psicossociais (pp. 99-148). São Paulo/Goiânia: Casa do Psicólogo/Universidade Católica de Goiás.

Dutra-Thomé, L. (2009). Exploração sexual e trabalho: um estudo de fatores de risco e proteção com adolescentes e jovens. Dissertação de Mestrado Inédita, Programa de Pós-graduação em Psicologia, Universidade Federal do Rio Grande do Sul, Porto Alegre, RS. Disponível em http://hdl.handle. net/10183/17211

Eschiletti-Pratti, L., Paula Couto, M. C. P., Moura, A., Poletto, M. \& Koller, S. (2008). Revisando a inserção ecológica: Uma proposta de sistematização. Psicologia: Reflexão e Crítica, 21 (1), 160-179.

Faleiros, V. P. (2004). O fetiche da mercadoria na exploração sexual. In R. M. C. Libório \& S. M.
G. Sousa (Orgs.), Exploração sexual de crianças e adolescentes no Brasil: reflexões teóricas, relatos de pesquisa e intervenções psicossociais (pp. 51-72). São Paulo/Goiânia: Casa do Psicólogo/Universidade Católica de Goiás.

Filgueiras, J. C. \& Hippert, M. I. (2002). Estresse: Possibilidades e Limites. In M.G. Jacques \& W. Codo (Eds.), Saúde mental e trabalho: leituras (pp. 112 129). Petrópolis, RJ: Vozes.

Forastieri, V. (1997). Children at work: Health and safety risk. Geneva: International Labour Office.

Habigzang, L. F., Azevedo, G. A., Koller, S. H. \& Machado, P. X. (2006). Fatores de risco e de proteção na rede de atendimento a crianças e adolescentes vítimas de violência sexual. Psicologia. Reflexão e Crítica, 19, 379-386.

Habigzang, L. F., Hatzenberger, R., Dala Corte, F., Stroeher, F. \& Koller, S. H. (2008). Avaliação psicológica em casos de abuso sexual na infância e adolescência. Psicologia. Reflexão e Crítica, 21, 338-344.

Human Rights Watch. (2001). Scared at school: Sexual Violence against girls in South African schools. New York: Author.

Jacques, M. G. (2002). "Doença dos nervos": uma expressão da relação entre saúde/doença mental. In M. G. Jacques \& W. Codo (Eds.), Saúde Mental e Trabalho: leituras (pp. 98-111). Petrópolis, RJ: Vozes, 2002.

Jacques, M. G. (2003). Abordagens teórico-metodológicas em saúde/doença mental e trabalho. Psicologia e Sociedade, 15 (1), 97-116.

Koller, S. H. \& De Antoni, C. (2004). Violência intrafamiliar: uma visão ecológica. In S. H. Koller (Ed.), Ecologia do desenvolvimento humano: pesquisa e intervenção no Brasil (pp. 293-310). São Paulo: Casa do Psicólogo.

Leal, M. L. P. (1999). A exploração sexual comercial de meninos, meninas e adolescentes na América Latina e Caribe [Relatório final]. Brasília: Centro de Referência, Estudos e Ações sobre Crianças e Adolescentes (CECRIA).

Libório, R. M. C. (2004). Exploração sexual comercial infanto-juvenil: categorias explicativas e políticas de enfrentamento. In R. M. C. Libório \& S. M. G. Sousa (Orgs.), Exploração sexual de crianças e 
adolescentes no Brasil: reflexões teóricas, relatos de pesquisa e intervenções psicossociais (pp. 19-50). São Paulo/Goiânia: Casa do Psicólogo/Universidade Católica de Goiás.

Libório, R. M. C. (2005). Adolescentes em situação de prostituição: uma análise sobre a exploração sexual comercial na sociedade contemporânea. Psicologia: Reflexão Crítica, 18 (3), 413-420.

Lima, S. M. \& Minayo-Gomes, C. (2003). Modos de subjetivação na condição de aprendiz: embates atuais. História, Ciências e Saúde-Manguinhos, 10 (3), 931-53.

Marques, M. E., Neves, M. de A. \& Neto, A. C. (2002). Trabalho infantil: a infância roubada. Belo Horizonte: Segrac.

Masten, A. S. (2001). Ordinary magic: Resilience processes in development. American Psychologist, 56 (3), 227-238. Disponível em www.capes.gov.br/ capes/portal

Mendes, A. M. \& Morrone, A. M. (2002). Vivências de prazer-sofrimento e saúde psíquica no trabalho: trajetória conceitual e empírica. In A. M. M. Mendes, L. O. Borges \& M. C. Ferreira (Eds.), Trabalho em transição, saúde em risco (pp. 25-42). Brasília: Editora Universidade de Brasília.

Morais, N. A. (2005). Um estudo sobre saúde de adolescentes em situação de rua: o ponto de vista de adolescentes, profissionais de saúde. Dissertação de Mestrado Inédita, Programa de Pós-graduação em Psicologia, Universidade Federal do Rio Grande do Sul, Porto Alegre, RS. Disponível em http:// hdl.handle.net/10183/7392

Morais, N. A. (2009). Trajetórias de vida de crianças e adolescentes em situação de vulnerabilidade social: entre o risco e a proteção. Tese de Doutorado inédita, Programa de Pós-graduação em Psicologia, Universidade Federal do Rio Grande do Sul, Porto Alegre, RS. Disponível em http://hdl.handle. net/10183/16660

Nardi, E. C. (2006). Ética, trabalho e subjetividade: trajetórias de vida no contexto das transformações do capitalismo contemporâneo. Porto Alegre: Editora do UFRGS.

Oliveira, C. R. de (1987). História do trabalho. São Paulo: Ática.
Organización Internacional del Trabajo. (2002). El trabajo decente es fundamental para el progreso social. Ginebra: Autor. Retrieved in April, 08, 2008, from http:||www-ilo-mirror.cornell.edu.public/spanish/ decent.htm

Organização Internacional do Trabalho. (2006). A eliminação do trabalho infantil: um objetivo ao nosso alcance [Relatório Global 2006. Suplemento Brasil]. Retrieved in March, 12, 2007, from http:// www.oitbrasil.org.br

Pesce, R. P., Assis, S. G., Santos, N. \& Oliveira, R. V. C. (2004). Risco e proteção: em busca de um equilíbrio promotor de resiliência. Teoria e Pesquisa, 20 (2), 135-143.

Pinheiro, P. S. (2009). Informe mundial sobre la violencia contra los niños y niñas. Ginebra: ONU.

Prieb, S. A. M. (2000). A tese do fim da centralidade do trabalho: mitos e realidades. Economia e Desenvolvimento, 12, 48-76.

Primer Congreso Mundial contra la Explotación Sexual Comercial de Niños, Niñas y Adolescentes. (1996, agosto). [Informe]. Retrieved in January 30th, 2009, from http://www.oit.org.pe/ipec/documentos/decla_estocolmo.pdf

Raffaelli, M., Koller, S. H., Reppold, C. T., Kuschick, M. B., Krum, F. M. B. \& Bandeira, D. R. (2001). How do Brazilian street youth experience 'the street'? Analysis of a sentence completion task. Childhood, 8, 396-415.

Sarriera, J. C., Silva, M. A., Kabbas, C. P. \& Lopes, V. B. (2001). Formação da identidade ocupacional em adolescentes. Estudos de Psicologia, 6 (1), 27-32.

Sarti, C. A. (1996). A família como espelho. São Paulo: Autores Associados.

Serpa, M. G. (2009). Exploração sexual comercial e prostituição: um estudo de fatores de risco e proteção com mulheres adultas e adolescentes. Dissertação de Mestrado Inédita, Universidade Federal do Rio Grande do Sul, Porto Alegre, Brasil. Disponível em http://hdl.handle.net/10183/17231

Somavia, J. (2001). Reducir el déficit del trabajo decente: un desafío global. Ginebra: OIT. Retrieved in April 08, 2008, from http: ||www-ilo-mirror.cornell.edu. public/spanish/bureau/dgo/messages/summary. htm 
United Nations International Children's Emergency Fund. (2004). Analyse régionale sur l'exploitation sexuelle en Afrique de l'Ouest et du Centre : évolution de la situation, progrès accomplis et obstacles à surmonter depuis le Congrès de Yokohama en 2001. West and Central Africa Regional Office: Author.

United Nations Secretary, General's Study on Violence against Children. (2005). Regional Desk Review: Latin America. Retrieved in January 30, 2009, from http://www.violencestudy.org/r27

Verado, M. T., Reis, M. S. F. \& Vieira, R. M. (1999).
Meninas do porto: mitos e realidade da prostituição infanto-juvenil. São Paulo: O Nome da Rosa.

Yin, R. K. (2005). Estudo de caso: planejamento e métodos ( $3^{\mathrm{a}}$ ed.). Porto Alegre: Bookman.

Zanini, P., Fürstenau, C. R., Pacini, L. \& Merlo, A. R. C. (2004). As transformações no serviço público e a saúde dos trabalhadores da seguridade social de Porto Alegre. In A. R. M. Crespo (Ed.), Saúde do trabalhador no Rio Grande do Sul: realidade, pesquisa e intervenção (pp. 361-378). Porto Alegre: Editora da UFRGS. 